\title{
Cytogenetical Studies on the Hybrids of Echinochloa oryzicola Vasing. and the Thai Tetraploid Strain of E. stagnina (Retz.) Beauv. with the West African Species E. obtusiflora Stapf
}

\author{
Tomosaburo Yabuno \\ College of Agriculture, University of Osaka Prefecture, \\ Sakai, 591 Japan
}

Received November 2, 1981

Species of the grass genus Echinochloa form a polyploid series with the basic chromosome number of $\mathrm{x}=9$ (Yabuno 1953, 1966). E. crus-galli (L.) Beauv. is an annual hexaploid species $(2 n=6 x=54)$ distributed throughout the world, rather more plentifully in warm temperate regions than in the tropics. This species is the presumable wild form of the Asian cultivated species E. utilis Ohwi et Yabuno (Yabuno 1953, 1962). The other annual species E. oryzicola Vasing. is distributed in Japan, Korea, China, U. S. S. R., Northern India, Sri Lanka, Italy, France and U.S. A. as a weed in lowland rice fields. This species is tetraploid with $2 n=4 x=36$ (Yabuno 1953). It was cytogenetically concluded that E. oryzicola is the donor of the two genomes to E. crus-galli (Yabuno 1966). Therefore the cytogenetical identification of diploid carrier of the third genome of E. crus-galli is the next main concern in the author's work. On the other hand a corm bearing, partially selfincompatible strain referred to as E. pyramidalis (Lamk.) Hitchc. et Chase was collected by Dr. A. V. Bogdan in Kitale, Kenya in 1964. This strain is diploid with $2 n=2 x=18$ (Yabuno 1968). Cytogenetical evidence indicated that the genome of the Kenyan diploid strain may be related to one of the two genomes of E. oryzicola (Yabuno 1976).

The self-pollinated, stoloniferous perennial species E. stagnina (Retz.) Beauv. occurs in swampy places or in floating rice fields as a weed in tropical Asia and Africa. The present author obtained the $4 x, 6 x, 12 x$ and $14 x$ strains which have been included under E. stagnina by taxonomists (Yabuno 1968, 1981 a). Cytological relationship between the $12 \mathrm{x}$ and $14 \mathrm{x}$ strains was described in a previous paper (Yabuno 1970). Since hybrid between the $4 x$ and $6 x$ strains has not yet been obtained, there is no evidence on their chromosomal relationship.

Recently the present author collected the annual diploid species E. obtusiflora Stapf in Nigeria.

Hybrids of E. oryzicola and the Thai $4 \mathrm{x}$ strain of E. stagnina with E. obtusiffora were artificially produced in 1980 . In this paper their cytological relationships are described. 


\section{Materials and methods}

Echinochloa obtusiflora collected in an upland rice field in Fufore, Nigeria, a Japanese strain of E. oryzicola and a Thai $4 \mathrm{x}$ strain referred to as E. stagnina were

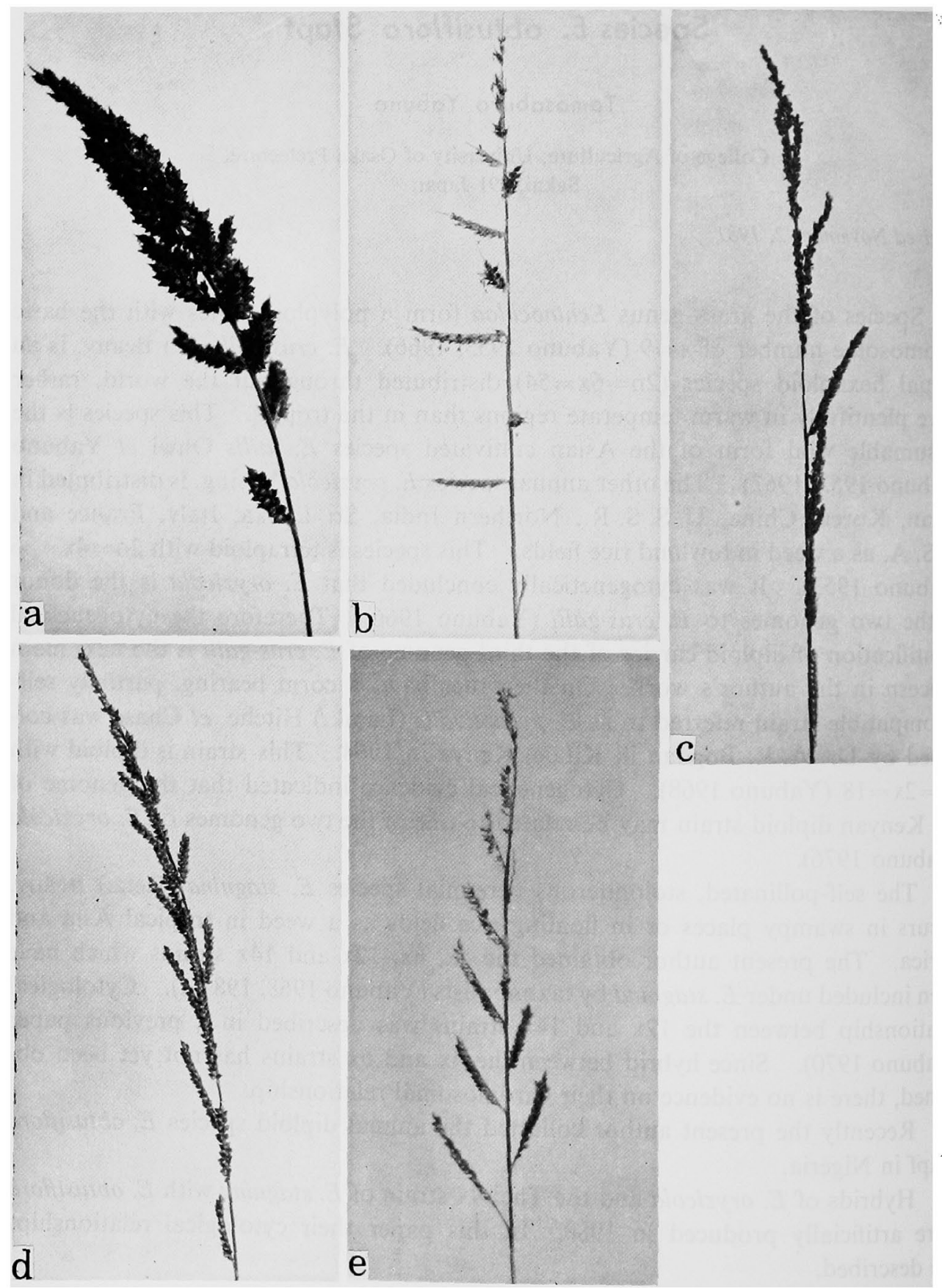

Fig. 1. Panicles of three Echinochloa species and their $F_{1}$ hybrids. a, E. oryzicola. b, The Thai tetraploid strain of E. stagnina. c, E. obtusiflora. d, the $\mathrm{F}_{1}$ of E. oryzicola $\times$ E. obtusiflora. $\mathrm{e}$, the $\mathrm{F}_{1}$ of $E$. stagnina (Thai strain) $\times$ E. obtusiflora. 
used in this study. Panicles of these three species are shown in Figs. 1-a, b, c. The technique of hybridization was same as that previously employed (Yabuno 1953). Young panicles of the resulting $F_{1}$ hybrids were fixed in Farmer's solution and processed as usual to make acetocarmine squash preparations of PMCs. A potassium iodide solution $\left(\mathrm{I}_{2}-\mathrm{KI}\right)$ was used to determine pollen stainability.

\section{Results}

General characteristics of the strains of E. oryzicola, E. stagnina and E. obtusiflora used in this study

The Japanese strain of E. oryzicola had the characteristics of the C-form, the surface of lemma of the lower floret being coriaceous, convex and lustrous, and was awnless. The lower floret sterile. The lower empty glume $1 / 2-3 / 5$ the length of the spikelet. The spikelets $4.5 \mathrm{~mm}$ long, $2.2 \mathrm{~mm}$ wide. The plant type erect.

The Thai $4 \mathrm{x}$ strain of $E$. stagnina was stoloniferous, and was of shorter stature as compared with the $6 \mathrm{x}, 12 \mathrm{x}$ and $14 \mathrm{x}$ strains which have been referred to as $E$. stagnina by taxonomists. The ligule transformed into hairs. The lower floret male. The spikelets $4.0 \mathrm{~mm}$ long, $1.5 \mathrm{~mm}$ wide, and awn $5 \mathrm{~mm}$ long.

Table 1. Seed fertility of two plants of E. obtusiflora following self- and cross-pollination

\begin{tabular}{|c|c|c|c|c|c|c|c|}
\hline \multirow{2}{*}{$\begin{array}{l}\text { Plant } \\
\text { no. }\end{array}$} & \multicolumn{3}{|c|}{ Seed fertility when selfed } & \multicolumn{3}{|c|}{$\begin{array}{c}\text { Seed fertility when bagged } \\
\text { together with a panicle of } \\
\text { another plant }\end{array}$} & \multirow{2}{*}{$\begin{array}{l}\text { Partner bagged } \\
\text { together }\end{array}$} \\
\hline & $\begin{array}{l}\text { No. of } \\
\text { florets }\end{array}$ & $\begin{array}{l}\text { No. of } \\
\text { seeds }\end{array}$ & $\begin{array}{l}\text { Seed fer- } \\
\text { tility }(\%)\end{array}$ & $\begin{array}{l}\text { No. of } \\
\text { florets }\end{array}$ & $\begin{array}{l}\text { No. of } \\
\text { seeds }\end{array}$ & $\begin{array}{l}\text { Seed fer- } \\
\text { tility }(\%)\end{array}$ & \\
\hline 4 & 2092 & 138 & 6.5 & 1007 & 419 & 41.6 & 12 \\
\hline 12 & 4363 & 193 & 4.4 & 4009 & 949 & 23.6 & 4 \\
\hline
\end{tabular}

E. obtusiflora was slightly tufted erect to $1 \mathrm{~m}$ high. Leaf $20-40 \mathrm{~cm}$ long, up to $9 \mathrm{~mm}$ broad. The ligule represented by a fringe of hairs. Panicles $10-30 \mathrm{~cm}$ long. The branches more or less erect. The lower floret male. The spikelets markedly blunt at the tip, $3 \mathrm{~mm}$ long, $1.5 \mathrm{~mm}$ wide, awnless, often in four rows. The lower empty glume obtuse, about a third as long as the spikelet. A chromosome number of $n=9$ was reported for this species for the first time by the present author (Yabuno 1981 a) (Figs. 2 a and b). When panicles of this species were self-pollinated by bagging, they showed a very low seed fertility in spite of their high pollen fertility. But when two panicles of different plants were bagged together, the seed fertility was remarkably improved, indicating the nature of partial self-incompatibility in this species (Table 1).

Morphology and cytology of the $F_{1}$ hybrids

The $\mathrm{F}_{1}$ hybrid, E. oryzicola $(\mathrm{n}=18) \times$ E. obtusiflora $(\mathrm{n}=9)$ :

A panicle of this hybrid is shown in Fig. $1 \mathrm{~d}$.

The surface of lemma of the lower floret was coriaceous, convex and shiny as that of the C-form of E. oryzicola. The lower floret male, and the ligule trans- 

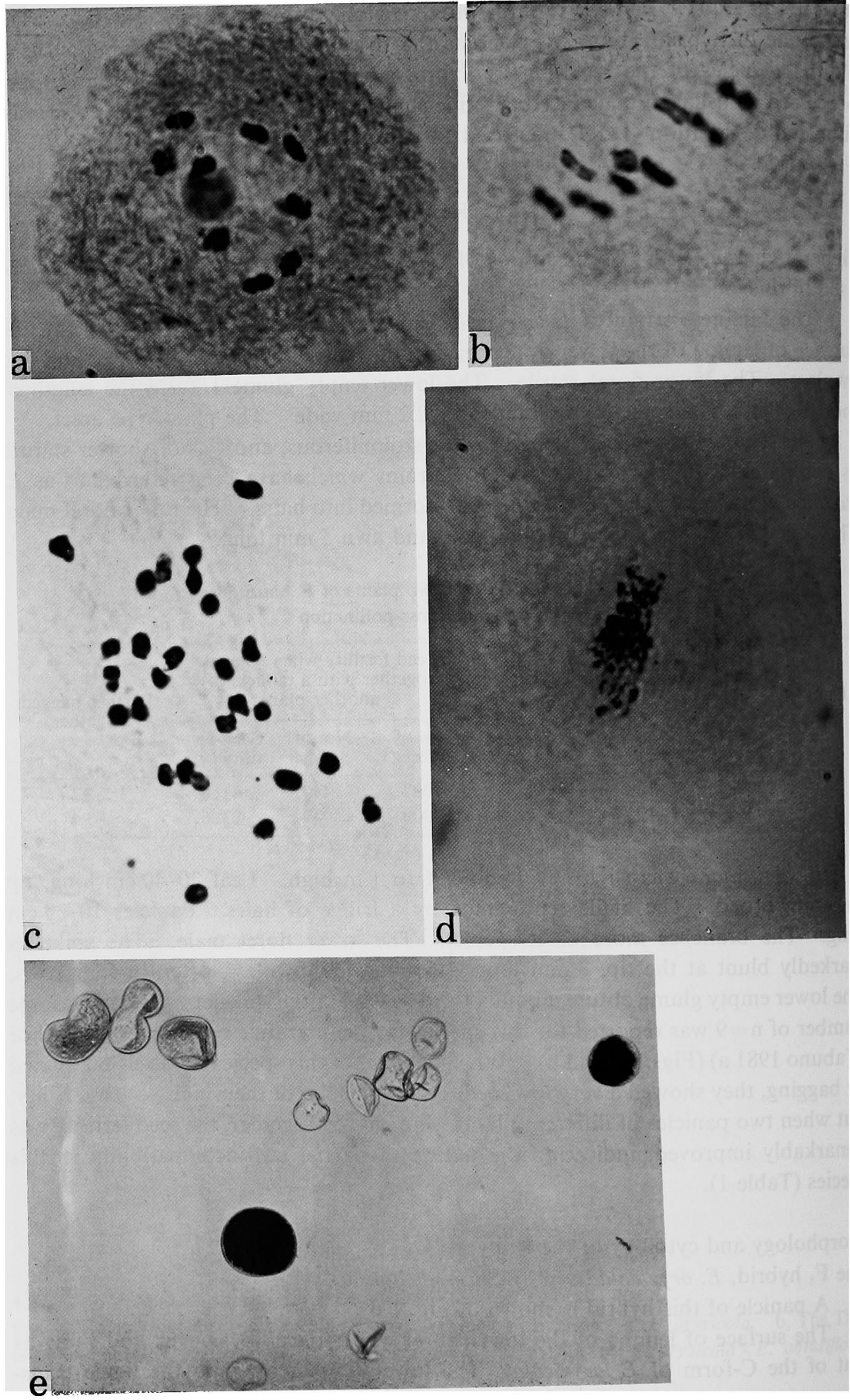
formed into hairs as that of E. obtusiflora. The spikelets $3.4-4.0 \mathrm{~mm}$ long, $1.8 \mathrm{~mm}$ wide. Although both parents were annual, the $F_{1}$ hybrid was unexpectedly perennial.

The data on chromosome configurations in the $F_{1}$ hybrid are presented in Table 2. Tri- and bivalents were formed, ranging from 0 to 1 , and 0 to 4 , respectively. All the bivalents were rods with a single terminalized chiasma. The univalents were irregularly scattered on the spindle, and some of them divided longitudinally at AI. About $30 \%$ of the PMCs had 27 univalents (Fig. 2 c). The mean chromosome configuration was $0.04_{\text {III }}+1.54_{\text {II }}+23.80_{I}$. This fact indicates that both genomes of E. oryzicola are different from the genome of E. obtusiflora. Restitution nuclei were occasionally observed in the first meiotic division (Fig. 2 d). The $F_{1}$ plant had $2.2 \%$ stainable pollen. The darkly stained pollen grains were usually larger than the empty ones (Fig. 2 e). The former might have an unreduced nucleus. Some pollen grains were dumb-bell shaped (Fig. 2 e).

Table 2. Chromosome configurations in the $F_{1}$ hybrids, E. oryzicola $(\mathrm{n}=18) \times$ E. obtusiflora $(\mathrm{n}=9)$

\begin{tabular}{cc}
\hline Configurations & No. of PMCs \\
\hline $27_{\mathrm{I}}$ & 32 \\
$1_{\mathrm{II}}+25_{\mathrm{I}}$ & 20 \\
$2_{\mathrm{II}}+23_{\mathrm{I}}$ & 19 \\
$3_{\mathrm{II}}+21_{\mathrm{I}}$ & 15 \\
$1_{\mathrm{III}}+2_{\mathrm{II}}+20_{\mathrm{I}}$ & $3\}$ \\
$4_{\mathrm{II}}+19_{\mathrm{I}}$ & 11 \\
$1_{\mathrm{III}}+3_{\mathrm{II}}+18_{\mathrm{I}}$ & 1 \\
\hline Mean chromosome configuration & 12 \\
\hline $0.04_{\mathrm{III}}+1.54_{\mathrm{II}}+23.80_{\mathrm{I}}$ & Total number of PMCs \\
\hline
\end{tabular}

The $\mathrm{F}_{1}$ hybrid, E. stagnina (Thai strain, $\left.\mathrm{n}=18\right) \times$ E. obtusiflora $(\mathrm{n}=9)$ :

A panicle of this hybrid is shown in Fig. 1 e.

The $F_{1}$ hybrid was stoloniferous perennial and morphologically resembled the Thai strain, but was awnless. The spikelets $3-4 \mathrm{~mm}$ long, $1.4 \mathrm{~mm}$ wide. The ligule represented by a fringe of hairs, and the lower floret male as those of the parents.

The data on chromosome configurations in the $F_{1}$ hybrid are presented in Table 3. Chromosome configuration in the $F_{1}$ hybrid was variable. There were 0 to 2 trivalents and 1 to 10 bivalents (Fig. 3). Some of the bivalents were ring type. The univalents usually splitted equationally at AI. The average chromosome configuration was $0.3_{\mathrm{III}}+6.1_{\mathrm{II}}+13.9_{\mathrm{I}}$. The pollen stainability was $0.09 \%$, and the selfed seed fertility was $0 \%$.

Fig. 2. a and b, diakinesis and $\mathrm{MI}$ in $E$. obtusiflora, respectively, showing $9_{\mathrm{Ir}}$. c, chromosome configuration at $\mathrm{MI}$ in the $\mathrm{F}_{1}$ hybrid of E. oryzicola $\times$ E. obtusiflora, showing $27_{\mathrm{I}}$. d, restitution nucleus in the first meiotic division in the $F_{1}$ hybrid. e, pollen grains of the $F_{1}$ hybrid. 


\section{Discussion}

The habitat of E. oryzicola $(\mathrm{n}=18)$ is confined to rice fields and considered as a companion weed of common rice Oryza sativa. E. phyllopogon Stapf subsp. oryzicola (Vasing.) Koss. is a synonym of this species (Yabuno 1981 b). It is assumed that E. oryzicola was introduced to U. S. S. R., Italy, France and U. S. A. from the Orient. According to Barrett and Seaman (1980), E. oryzicola was probably introduced as rice seed contaminant at the begining of rice culture in California, the 1920's, and rice agronomists in California have referred to this species as "Japanese, Orient or White Water Grass".

Table 3. Chromosome configurations in the $F_{1}$ hybrid, E. stagnina (Thai strain, $\mathrm{n}=18) \times$ E. obtusiflora $(\mathrm{n}=9)$

\begin{tabular}{|c|c|}
\hline Configurations & No. of PMC \\
\hline $1_{\mathrm{II}}+25_{\mathrm{I}}$ & 1 \\
\hline $2_{\mathrm{II}}+23_{\mathrm{I}}$ & 1) \\
\hline $1_{\mathrm{III}}+1_{\mathrm{Ir}}+22_{\mathrm{r}}$ & $2\}$ \\
\hline $3_{\mathrm{II}}+21_{\mathrm{I}}$ & 4 \\
\hline $4_{I I}+19_{I}$ & $5)$ \\
\hline $1_{\mathrm{III}}+3_{\mathrm{II}}+18_{\mathrm{I}}$ & $1\}$ \\
\hline $2_{\text {III }}+2_{\text {II }}+17_{\text {I }}$ & $1)$ \\
\hline $5_{\mathrm{II}}+17_{\mathrm{I}}$ & 10) \\
\hline $1_{\mathrm{III}}+4_{\mathrm{II}}+16_{\mathrm{I}}$ & 3) 13 \\
\hline $6_{\mathrm{II}}+15_{\mathrm{I}}$ & $11\}_{14}$ \\
\hline $1_{\mathrm{III}}+5_{\mathrm{II}}+14_{\mathrm{I}}$ & $3\}^{14}$ \\
\hline $7_{\mathrm{II}}+13_{\mathrm{I}}$ & 17) \\
\hline $1_{I I I}+6_{I I}+12_{I}$ & 9\} 27 \\
\hline $2 I I I+5 I I+11_{I}$ & 1) \\
\hline $8_{I I}+11_{I}$ & $8)$ \\
\hline $1_{\text {III }}+7_{\text {II }}+10_{\text {I }}$ & 6) 15 \\
\hline $2 \mathrm{III}+6_{\mathrm{II}}+9_{\mathrm{I}}$ & 1) \\
\hline $9_{\mathrm{II}}+9_{\mathrm{I}}$ & 9) 10 \\
\hline $1_{I I I}+8_{I I}+8_{I}$ & 1\} 10 \\
\hline $10_{I I}+7_{I}$ & 1) \\
\hline $1_{I I I}+9_{I I}+6_{I}$ & $1\}$ \\
\hline $\begin{array}{c}\text { Mean chromosome } \\
\text { configuration } \\
0.3_{\mathrm{III}}+6.1_{\mathrm{II}}+13.9_{\mathrm{I}}\end{array}$ & $\begin{array}{c}\text { Total number } \\
\text { of PMCs } \\
96\end{array}$ \\
\hline
\end{tabular}

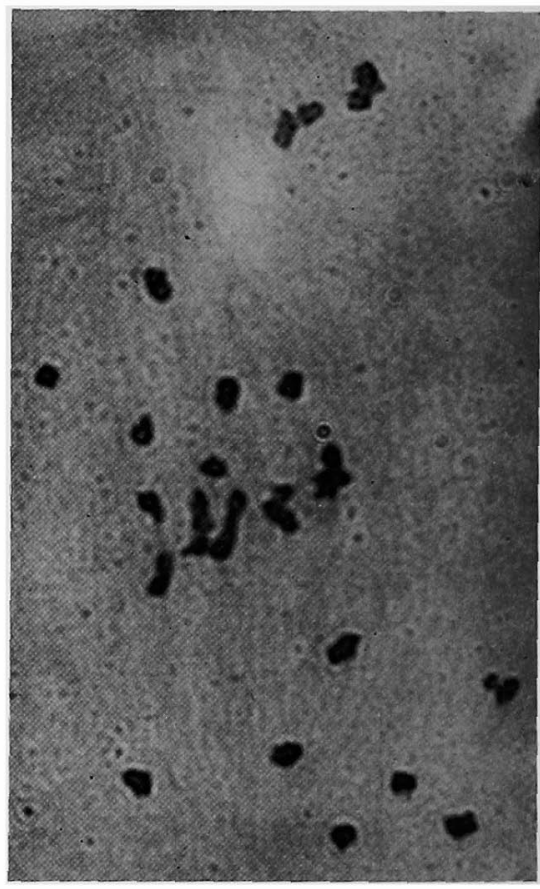

Fig. 3. Chromosome configuration at $\mathrm{MI}$ in the $\mathrm{F}_{1}$ hybrid of E. stagnina (Thai strain) $\times E$. obtusiflora, showing $5_{\mathrm{II}}+17_{\mathrm{I}}$.

E. crus-galli $(\mathrm{n}=27)$ is a phenotypically and ecologically extremely polymorphic species. This species is distributed rather more plentifully in warm temperate regions than in the tropics, and usually grows in swampy places. In the meiosis in the $F_{1}$ hybrid, E. crus-galli $(\mathrm{n}=27) \times E$. oryzicola $(\mathrm{n}=18)$, chromosome configurations $18_{\mathrm{II}}+9_{\mathrm{I}}$ and $1_{\mathrm{III}}+17_{\mathrm{II}}+8_{\mathrm{I}}$ were formed with high frequencies, total up to $98 \%$ of the PMCs (Yabuno 1966). Therefore the present author assumed that two of the three genomes of E. crus-galli are homologous to those of E. oryzicola. On the basis of evidence from morphology, cytology and geographical distribution, it was concluded that E. crus-galli is an allohexaploid produced by the natural hybridi- 
zation of E. oryzicola with a not-yet-discovered diploid species of Echinochloa or its related genus and by the subsequent chromosome doubling (Yabuno 1966).

The $\mathrm{F}_{1}$ hybrid of E. oryzicola with the Kenyan diploid strain referred to as $E$. pyramidalis had a mean chromosome configuration of $0.2_{\mathrm{III}}+6.0_{\mathrm{II}}+14.4_{\mathrm{I}}$ (Yabuno 1976). This indicates that the genome of the Kenyan diploid strain is related to one of the gnomes of E. oryzicola. While on the other hand the mean chromosome configuration in the $\mathrm{F}_{1}$ hybrid of E. oryzicola $(\mathrm{n}=18) \times$ E. obtusifora $(\mathrm{n}=9)$ was $0.04_{\mathrm{III}}+1.54_{\mathrm{II}}+23.80_{\mathrm{I}}$. The most characteristic feature of chromosome configuration in this hybrid was the high frequency of univalents. Moreover this hybrid was rarely capable of producing unreduced nuclei in the first division in PMCs. Therefore it may be said that the West African diploid species E. obtusiflora has more or less the cytological characteristics which are requisite for a donor of the third genome present in the hexaploid E. crus-galli.

At present the diploid species of Echinochloa are known only from Africa. But when the distributional patterns of E. oryzicola and E. crus-galli are considered, the possibility of diploid carrier of the third genome being Oriental species cannot be ruled out. Further collection of diploid species of Echinochloa and studies on species hybrids are required to elucidate the origin of the third genome of E. crusgalli.

E. stagnina is distributed in tropical Asia and Africa. The $4 \mathrm{x}, 6 \mathrm{x}, 12 \mathrm{x}$ and $14 \mathrm{x}$ strains which have been treated as $E$. stagnina by taxonomists are different from each other not only in chromosome number but also in some morphological characters (Yabuno 1968). $\quad F_{1}$ hybrid between $4 x$ and $6 x$ strains has not yet been obtained. Therefore at present their genomic constitutions are not distinct. But in this study it was elucidated that one of the two genomes of the Thai $4 \mathrm{x}$ strain of E. stagnina may be partially homologous to the genome of $E$. obtusiflora.

E. obtusiflora has been collected in Gurin, Fufore, Yola, Jalingo, Fika, Gombe, Gaya, Jos, Katsina, Zaria, Kaduna, Wurno and Tegina, Nigeria and in Maroua, Cameroun. These collection sites in Nigeria are localized in the area where African rice Oryza glaberrima is predominantly cultivated. The present author confirmed in Nigeria that $E$. obtusiflora occurs in shallow pools or wet places often mixed with E. pyramidalis and also in upland rice fields in the northern area. This fact suggests that the distribution of E. obtusiflora has been connected with African rice cultivation. E. obtusiflora has been much less known but the present author regards this species as a companion weed of African rice $O$. glaberrima.

\section{Summary}

The West African annual diploid E, obtusifora $(2 n=2 x=18)$ is characterized by the morphology of its spikelets and is partially self-incompatible. The result of the author's field observation in Nigeria indicated that this species is a companion weed of African rice Oryza glaberrima. The annual tetraploid E. oryzicola $(=E$. phyllopogon Stapf subsp. oryzicola (Vasing.) Koss., $2 \mathrm{n}=4 \mathrm{x}=36$ ) is a companion weed of common rice Oryza sativa, and also is the carrier of two of the three genomes of the annual hexaploid E. crus-galli $(2 \mathrm{n}=6 \mathrm{x}=54)$, the wild form of the Asian cultivated species $E$. utilis. The self-pollinated, stoloniferous perennial species $E$. stagnina is 
distributed in tropical Asia and Africa, and includes some cytoytpes. The $F_{1}$ hybrids of $E$. oryzicola and the Thai $4 \mathrm{x}$ strain $(2 \mathrm{n}=4 \mathrm{x}=36)$ of $E$. stagnina with E. obtusiflora were artificially produced. The results of the cytogenetical studies on these $\mathrm{F}_{1}$ hybrids indicated that the genome of $E$. obtusiflora may be related to one of the genomes of the Thai $4 \mathrm{x}$ strain and that E. obtusiflora has more or less the cytological characteristics which are requisite for a presumable diploid carrier of the third genome of E. crus-galli.

\section{References}

Barrett, S. C. H. and Seaman, D. E. 1980. The weed fiora of Californian rice fields. Aquatic Botany 9: 351-376.

Yabuno, T. 1953. Morphological and cytological studies in the genus Echinochloa. Seiken Zihô 6: 66-71.

- 1962. Cytotaxonomic studies on the two cultivated species and the wild relatives in the genus Echinochloa. Cytologia 27: 296-305.

- 1966. Biosystematic study of the genus Echinochloa. J. J. Bot. 19: 277-323.

- 1968. Biosystematic study of Echinochloa stagnina (Retz.) P. Beauv. and E. pyramidalis (Lamk.) Hitchc. et Chase. Cytologia 33: 508-519.

- 1970. Biosystematics of Echinochloa stagnina (Retz.) P. Beauv., cytological relationship between the 12- and 14 ploid strains. Genetica $41: 311-315$.

- 1976. Cytological relationship between the Kenyan diploid strain of Echinochloa pyramidalis (Lamk.) Hitchc. et Chase $(\mathrm{n}=9)$ and E. oryzicola Vasing. $(\mathrm{n}=18)$. Cytologia 41: 679-684.

- 1981a. The classification and geographical distribution of the genus Echinochloa (in Japanese). Biosystematic Research 5: 86-97.

-1981b. Cytological relationship between Echinochloa oryzicola Vasing. and the French strain of E. phyllopogon Stapf subsp. oryzicola (Vasing.) Koss. Cytologia 46: 393-396. 